\title{
CHALLENGES TO SEISMIC REHABILITATION DECISION PROCESS IN NEW ZEALAND: A FOCUS OF DECISION ENVIRONMENT
}

\author{
Fei J. YING a,*, Suzanne WILKINSON ${ }^{b}$, Jim CORNER c \\ a School of Engineering, Auckland University of Technology, Private Bag 92006, Auckland 1142, \\ New Zealand \\ ${ }^{b}$ Department of Civil and Environmental Engineering, University of Auckland, New Zealand \\ ${ }^{c}$ Department of Management System, University of Waikato, New Zealand
}

Received 27 February 2015; accepted 24 October 2015

\begin{abstract}
Implementing seismic rehabilitation requires a substantial investment for substandard building owners. Seismic retrofitting can significantly reduce earthquake damages to the built environment and thus decrease the risk posing to the public and the community. However, many countries with active seismic zones, including New Zealand, experience slow progress of seismic retrofit. This paper examines the decision environment which has significant impact on stakeholders' behaviours, to identify challenges in seismic rehabilitation decision-making. A qualitative approach was adopted with semi-structured interviews. A selection of building owners, government officials, and practical professionals involved in seismic retrofitting decision-making were interviewed. Major challenges identified by the interview results include various options, diverse considerations, assorted stakeholders, conflicting multiple objectives, and unaided decision making process. The inconsistency in expectation of whether building owners have sufficient aid in decision-making process offers plausible explanation regarding the key impediment to successful seismic rehabilitation decisions. A decision-making model is thus a necessity to assist building owners making an informed decision.
\end{abstract}

KEYWORDS: Earthquake-prone buildings; Seismic mitigation; Building owners; Decision environment

\section{INTRODUCTION}

Major earthquake events (magnitude more than 7) are low probability, high consequence events that usually cause fatalities, damage to properties and infrastructure, and social disruption. Earthquake losses can be mitigated or avoided with the appropriate seismic rehabilitation (Bostrom et al. 2006). In particular, the implementation of seismic mitigation of earthquake-prone buildings (EPBs) can significantly reduce earthquake damage to the built environment (Spence 2004). Traditionally, many countries within active seismic zones have largely focused on three approaches to reduce losses from earthquake disasters: understanding the scientific nature of earthquakes, developing technical design solutions, and using regulatory frameworks. However, these efforts have not yet yielded in satisfactory outcomes (Tierney 2004; FEMA 2006). Unsafe buildings are still visible in

* Corresponding author. E-mail: fei.ying@aut.ac.nz many earthquake prone areas, despite extensive research on seismic retrofitting. Similarly, New Zealand experiences slow progress of seismic retrofitting EPBs which poses major risk to the public and community (Bothara, Sharpe 2009). This is evident from the enormous losses from the Christchurch earthquake which could have been reduced if mitigation programmes had been implemented before the disaster happened.

It is well recognised that the decision to improve seismic performance of a building is complicated (Earthquake Engineering Research Institute 1998). Rehabilitating EPBs involves addressing both the risks in EPBs and those to the multi-disciplined stakeholders, such as building owners, engineers and government officers, involved in the decision-making process (Bostrom et al. 2006). Thus, seismic retrofitting of EPBs requires a multi-disciplinary approach rather than just an engineering one, starting from the defi- 
nition of a safe building to approaches adopted for implementation (Bothara, Sharpe 2009). This thus renders seismic retrofitting decision-making challenging.

Previous research have investigated several institutional, socio-behavioural, political and regulatory challenges to successful earthquake risk mitigation, such as risk perception, mitigation cost, efficacy of mitigation measures, and the use of regulatory mechanisms (Solberg et al. 2010; Paton et al. 2010; Egbelakin et al. 2013). However, little attention has focused on the multi-disciplined decision environment of the seismic rehabilitation decision process. The complexity in earthquake risk mitigation particular to the multi-disciplinary stakeholders includes building owners assessment of recommendations from various stakeholders who are influenced by their diverse backgrounds, understanding and knowledge of EPBs and levels of involvement in making the final decision. Arguably, these stakeholders have varying impacts in a building owner's decision process. The context in which each decision is made is a major determinant and many priorities and trade-offs are considered during the process. The decision environment thus has a significant impact on stakeholders' behaviours and is essential to assure effective policy implementation. Furthermore, the magnitude of building collapses and fatalities from the recent Christchurch earthquakes in New Zealand suggests that adequate risk mitigation measures were not adopted for EPBs \{Canterbury Earthquake Royal Commission, 2012 \#522\}(Canterbury Earthquake Royal Commission 2012). The unwillingness among EPBs' owners has been a critical issue in reducing the impact of earthquake at pre-disaster stage.

This study was initiated by the need to mitigate earthquake risks of the built environment by examining why building owners are unwilling or delaying retrofit their EPBs. The objective of this study was to investigate the characteristics of major stakeholders' decision environment and identify key impediments affecting building owners' seismic retrofitting decisions.

\section{SEISMIC RISK MITIGATION IN NEW ZEALAND}

The New Zealand government enacted legislation in the Building Act 2004 to reduce both fatalities and financial damages from EPBs. An EPB is considered in this research as a building that will have its ultimate capacity exceeded in a moderate earthquake and would likely collapse causing in- jury or death to persons in the building or those on any other property or damage to any other property (Department of Building and Housing 2004). A moderate earthquake is legally defined as an earthquake that would generate shaking at the site of the building that is of the same duration, but that is one-third as strong, as the earthquake shaking (determined by normal measures of acceleration, velocity and displacement) that would be used to design a new building at the site (Ministry of Businesss Innovation \& Employment 2013). As the result of a comprehensive review of Building Act 2004 carried out during 2009 and 2010, the Building Amendment Act 2013 came into force on 1 January 2015.

The reviewed Building Act seeks to protect people from serious harm in moderate earthquake (Ministry of Businesss Innovation \& Employment 2013). The legislation has several implications affecting the adoption of seismic mitigation measures. Sections 112-113 of the Act stipulate that an existing building that requires alteration or a change of use must comply with the building code in the same manner as a new building. Consequently, seismic retrofitting of EPBs often triggers other building code requirements such as fire performance, parking requirements, and disability access, and thus results in additional design plan and cost implications.

Building Act 2004 recommends a minimum seismic retrofit level of $33 \%$ of the strength of a new building, referred to as the National Building Standard (NBS). However, the New Zealand Society for Earthquake Engineering (NZSEE), a distinguished organisation having significant impact on earthquake engineering, considers the minimum requirement of $33 \%$ NBS is not adequate to completely eliminate critical structural weakness (NZSEE 2006). The NZSEE considers a $67 \%$ NBS as a more suitable minimum standard. Subsequently, the minimum earthquake performance level adopted by the Act is deferred from the NZSEE's recommendation of a higher seismic performance stand for buildings. This has created confusion amongst building owners and other retrofit stakeholders regarding the retrofit level (Egbelakin, Wilkinson 2008). As the result, local council reported that $65 \%$ of the identified potential EPBs owners did not respond to the notices issued to them, while $43 \%$ of EPBs owners who responded requested time extensions ranging from 15 years to 25 years to seismically retrofit their EPBs (Stevens, Wheeler 2008). This low response from EPBs owners indicates that they are incapable to make 
appropriate decisions to adopt seismic retrofitting measures.

Seismic risk mitigation involves making the decision to reduce the built environment's vulnerability in earthquakes (Earthquake Engineering Research Institute 1998). For the purpose of this study, seismic risk mitigation decisions refer to the choices made by building owners to adopt predisaster seismic adjustment. Stakeholders involve in earthquake risk mitigation include owners of buildings, central government, local councils, and related professionals such as engineers ( $\mathrm{Su} 2009$; Lindell et al. 1997). These stakeholders operate in different decision environments, and have direct impacts on building owners' earthquake mitigation decisions. Among these stakeholders, building owners are vital to seismic risk mitigation decision because they are responsible for making the final decisions whether or not to adopt mitigation measures (Lindell et al. 1997). This decisions is often an outcome of information received from the various stakeholders. During the decision-making process, context plays an important role and there are many trade-offs (Bartels et al. 2015). The interplay between these stakeholders' activities and decision environments is a major determinant helping to form the seismic risk mitigation adopted by building owners.

Seismic risk mitigation decision-making process involves multi-disciplined stakeholders, which renders seismic retrofitting projects challenging (Bostrom et al. 2006). Building owners of EPBs assess the recommendations form the diverse set of stakeholders whose contributions are adjusted by their requirements, wishes and concerns related to the project, along with their project success criteria (Eskerod, Huemann 2014). These stakeholders have various levels of involvement in making the final decisions, and thus diverse impacts on a building owner's concluding risk mitigation decision. Involving the opinions of major stakeholders in seismic risk mitigation decisions has been largely ignored in previous research. Hence, stakeholders' opinions and perspectives need to be addressed when examining earthquake risk mitigation decisions, because a successful mitigation decision requires effective participation of all stakeholders.

\section{RESEARCH METHOD}

The purpose of this study was to identify the challenges and obstacles encountered by key stakeholders in seismic mitigation by gaining a detailed understanding of the seismic decision environment. The focus of the work is on identification of main characteristics in the decision environment. It also seeks to recognise the obstacles in making a decision for EPBs, as well as questions of how and why behaviour occurs. The emergence of how and why questions resulted in adopting exploratory qualitative research and choosing interviewing as the research method (Creswell 2007). The main research questions explored were:

RQ1. Why are building owners generally inefficient in making decisions of their EPBs mitigation?

RQ2. What are the key variables considered during the decision-making process?

RQ3. How can building owners be assisted to make effect and efficient decisions on their EPBs mitigation?

Semi-structured interviews were chosen to allow an in-depth understanding of the topic. Using intensive probing questions, face-to-face interviews also provides opportunity to explore the reasons for a person's response to gain more insight into the research problem. Using interviewing technique, it is possible for different stakeholders involved in seismic mitigation to describe their understanding of challenges in the development of retrofitting solutions across different seismic-risk regions.

A purposeful sampling method was employed to select the participants in this study. According to Maxwell (2013), purposeful sampling is a strategy in which, "particular settings, persons, or events are deliberately selected to provide an in-depth and relevant information on the research problem that are difficult to get". It is extremely challenging to enumerate the population sample frame, due to very limited prior data on building owners and other stakeholders that were involved in the seismic rehabilitation project. This sampling method is appropriate in the context of this study because it allows the research team to select participants based on their relevance to the research topic and objectives, as well as geographic location, knowledge and experience in seismic mitigation implementation.

Individual stakeholders involved in the decision-making process of seismic mitigation were considered as the unit of analysis. Three New Zealand cities were chosen in accordance with hazard factor, seismicity, percentages of EPBs, and mitigation approach, as shown in Table 1 . The variety of different parameters allows a comprehensive view of the decision environment. 
Table 1. Summary of participated cities' characteristics

\begin{tabular}{llll}
\hline Category & Auckland & Christchurch & Wellington \\
\hline Hazard factor $(\mathrm{Z})$ & 0.13 & 0.22 & 0.40 \\
Level of earthquake risks & Low & Medium & Very High \\
Percentage of EPBs & 42 & 48 & 52 \\
Retrofit standard adopted & $33 \% \mathrm{NBS}$ & $33 \% \mathrm{NBS}$ & $52 \% \mathrm{NBS}$ \\
Mitigation approach & Passive & Active/passive & Active \\
Population & $1,354,900$ & 390,300 & 389,700 \\
No. of interviewees & 10 & 8 & 14 \\
\hline
\end{tabular}

Notes: Hazard factor (Z): equivalent to an acceleration coefficient with an annual probability of exceedance in $1 / 500$ for different locations in New Zealand (Standards New Zealand 2004).

The key stakeholders selected for the research include building owners (BO), practical professionals (PRO) and government organisations (GO), both central and local governments. All participants must have been involved in retrofitted EPBs projects in the last two years. This allowed the researcher to develop an understanding of the decision environment from different aspects. It also made possible establishing the characteristics of the decision environment from a holistic viewpoint. Table 2 summarises the difference characteristics of the participants, used as the main unit of analysis. About 38\% were building owners, $28 \%$ were officers from government organisations, while $34 \%$ were professionals practicing in engineering, architect and other areas. The majority of the participants are in the senior management category. The average working experience of participants in seismic mitigation is 8.2 years, which indicates that most respondents have justifiable experience in seismic mitigation, thus increasing the reliability of the data.

Table 2. Profile of interview participants

\begin{tabular}{llll}
\hline Characteristic & Category & No. & $\%$ \\
\hline Participants & Building owners (BO) & 12 & 38 \\
& Government organisations (GO) & 9 & 28 \\
& Practical professionals (PRO) & 11 & 34 \\
Type of & Public & 5 & 42 \\
ownership & Private & 4 & 33 \\
& Non-profit & 3 & 25 \\
Type of & Engineer & 5 & 46 \\
professionals & Architect & 3 & 27 \\
& Quantity surveyor & 2 & 18 \\
& Business consultant & 1 & 9 \\
Location & Auckland & 10 & 31 \\
& Christchurch & 8 & 22 \\
& Wellington & 14 & 47 \\
\hline
\end{tabular}

In order to analyse the data collected, the recorded interviews were transcribed. The transcripts provided a comprehensive record of the interviews that provided the foundation of the thematic analysis for further discussions. The main aim of the data analysis was to identify trends or themes that appeared in individual interviews, or reappeared among various interviews. Attention was paid to "how" and "why" words to discover the characteristics of the decision environment and challenges expressed by the participants. NVIVO qualitative data analysis software was used to analyse the interview transcriptions thematically. Industry experts reviewed the findings for comments and confirmation in order to establish data validity.

\section{KEY FINDINGS}

The main aim of this paper was to examine the decision environment of decision making process in seismic retrofitting projects and to understand the obstacles in making an informed decision. This section of the paper is focused on presenting the nature of these obstacles and offers an informed explanation as to why slow progress on seismic retrofit is experienced in New Zealand. Various themes related to challenges appeared during the analysis of interview results, as summarised in Table 3. The rank of each challenge is determined in accordance with the total number of participants who mentioned this specific consideration as part of the decision-making environment; the more participants considered it; and the higher the rank. Figure 1 illustrates the composition of participants supporting each challenge identified in the decision environment. 
Table 3. Decision-making challenges embedded in the decision environment

\begin{tabular}{|c|c|c|c|c|c|}
\hline & llenges & Category & Frequency & $\%$ in the & Total \\
\hline A & Various possible options in mitigating seismic risk & $\mathrm{BO}$ & 12 & 100 & 32 \\
\hline & & GO & 9 & 100 & \\
\hline & & PRO & 11 & 100 & \\
\hline B & Diverse considerations & BO & 10 & 83 & 24 \\
\hline & & GO & 7 & 78 & \\
\hline & & PRO & 7 & 64 & \\
\hline $\mathrm{C}$ & Assorted stakeholders involved in reaching the decision & $\mathrm{BO}$ & 8 & 67 & 20 \\
\hline & & GO & 5 & 56 & \\
\hline & & PRO & 7 & 64 & \\
\hline $\mathrm{D}$ & Conflicting multiple objectives & $\mathrm{BO}$ & 10 & 83 & 19 \\
\hline & & GO & 3 & 33 & \\
\hline & & PRO & 6 & 55 & \\
\hline $\mathrm{E}$ & Unaided decision making process & $\mathrm{BO}$ & 9 & 75 & 13 \\
\hline & & GO & 2 & 22 & \\
\hline & & PRO & 2 & 18 & \\
\hline
\end{tabular}
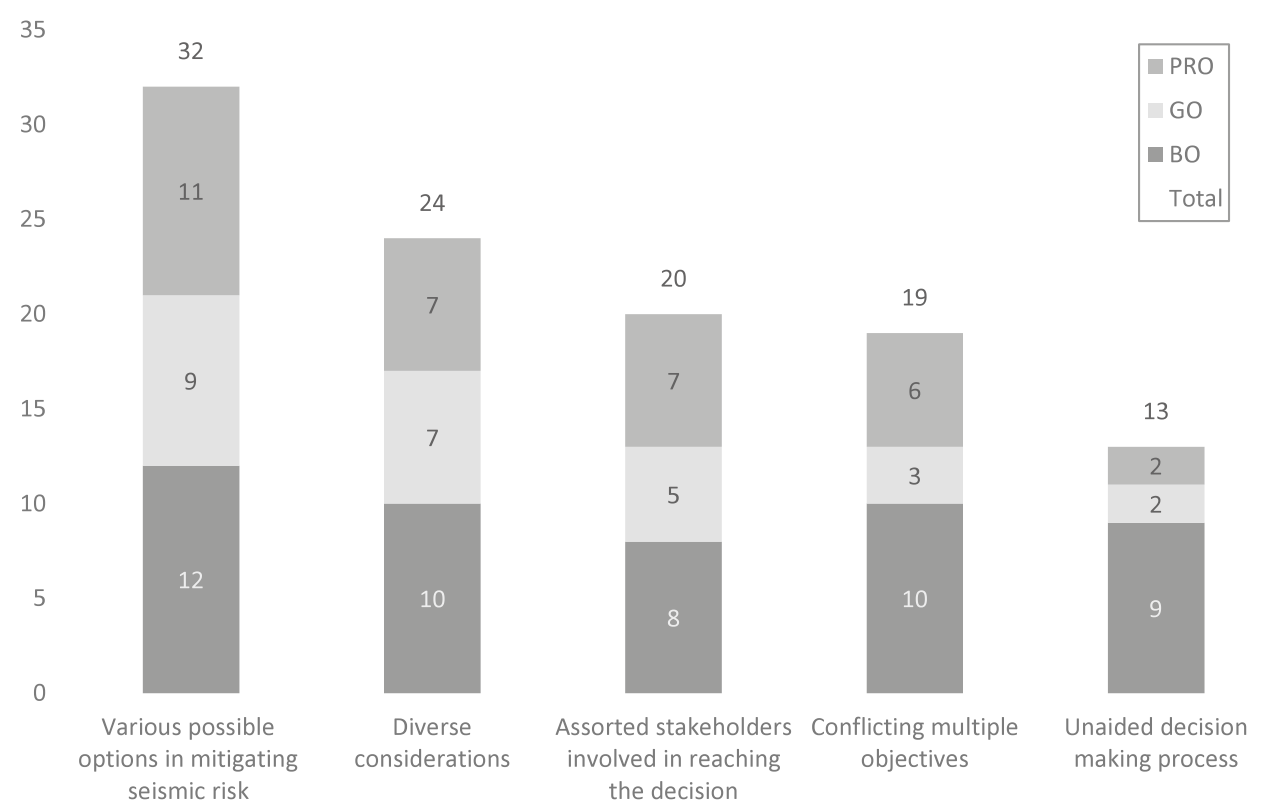

Fig. 1. The composition of participants identifying each challenge

\section{Various possible options in mitigating seismic risk}

All the participants recognised that various alternatives had to be considered while implementing seismic mitigation as a significant challenge in decisions-making. "In a building owner's mind, whether or not to rehabilitate the building's (seismic) performance is a small corner of a huge iceberg (PRO, Engineer3)." Reflecting the theory of risk management, building owners indeed have several options in managing seismic risks, involving both physical and economic losses. These alternatives can involve one or a combination of risk treatment methods, such as risk retention, risk reduction, risk transfer, and risk avoidance. Building owners who have EPBs can choose implementing seismic mitigation measures, or passing the possible losses to other parties, as well as purchasing insurance. If the risk seems too large or unmanageable, the owner may decide to sell the building as the ultimate solution of passing on the possible loss to the next building owner. These options are not always mutually exclusive, which means one or a combination of these measures can be adopted, in accordance with owners' affordability and attitudes toward the risk. Therefore, there 
are many available risk-relevant alternatives for building owners to consider. Implementing seismic mitigation measures to reduce the risk is only one of many options, or part of one option.

Moreover, once deciding to retrofit the EPBs, building owners have to determine the level to which the building is to be raised. Engineers normally provide plans of seismic retrofitting to $33 \%$ NBS, $67 \%$ NBS or as practical as possible to be assessed by building owners, thanks to the inconsistency of recommended retrofitting level by the Building Act 2004 and NZSEE. "The board could not make up their mind on which level we should bring our building to. We had a bad experience with [another EPB building]. It was retrofitted to the required level by that time, and now is a listed EPB again (BO, Public 2)." The building owners are concerned that the Building Code will be reviewed with input from consumers, the building industry, and central and local governments in the near future, as stated in the reviewed Building Act. Thus, the inconsistency of NZSEE recommendation implies that the seismic retrofit level might be increased. Previous experience often shows that buildings which were seismic rehabilitated a few years earlier might again considered to be earthquake prone buildings. It takes a significant amount of money to improve the status of these EPBs, not to mention the possible business interruption and other negative impacts on the owners. When making such a decision, building owners have to consider the costs, timeframe, funding scheme and cash flow for each option, i.e. 34\%NBS, $67 \%$ NBS, and maximum NBS. It is therefore a demanding task for building owners to determine the strengthen level.

\section{Diverse considerations}

Analysis of the research data showed that diverse considerations building owners encountered during the decision-making process pose a major challenge leading to inefficient seismic mitigation implementation. In all, $92 \%$ of the building owners and $82 \%$ of the professional recognise this quality, $67 \%$ of governmental personnel identified it in the interviews, as illustrated in Figure 2.

A complex array of factors and considerations were summarised from the interview results in accordance with the frequency mentioned and discussed by the participants. These considerations cover a wide range of factors in relation to seismic risk, regulatory requirements, costs and existing building performance, to name a few. They cover

\section{DIVERSE CONSIDERATIONS}

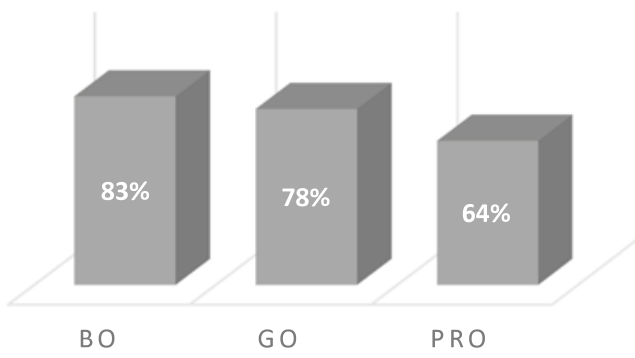

Fig. 2. The percentage of participant recognising "Diverse considerations with uncertainty" as a challenge

the aspects of engineering, business, legislation and risk management. The diversity of various considerations truly reflects the multi-disciplinary aspect of the decision environment.

Furthermore, these considerations in the decision environment involve a certain amount of uncertainty, such as in assessing future earthquakes, seismic mitigation costs and the expectation of building performance in certain levels of earthquake. Although the professionals in different fields are making steady progress to model various scenarios, uncertainty is still a considerable impediment in efficient seismic mitigation decision-making. For example, hidden costs associated with retorting EPBs involve high uncertainty in estimating retrofitting costs. These costs relate to expenditure that cannot be estimated until the retrofitting work commences or is competed (Bradley et al. 2008). Hidden costs are affected by several variations that complicate the estimation of the overall retrofitting cost. These variations depend on factors such as building characteristics, type of structure, existing building performance, and other works relating to the provisions in the building code that triggered by retrofitting scheme. "A proposal from our engineers suggests that the total costs of the rehabilitation may vary from $-20 \%$ to $140 \%$ (BO, Private 2)." This is not unusual for a seismic mitigation project, due to many uncertain engineering considerations including geotechnical and building service conditions. With such a wide range of cost estimates, the participant felt that it was extremely challenging to draw a conclusion. Building owners constantly found themselves caught by "surprises".

Making the decision problem thornier, many building owners and professionals reported that these factors are normally interdependent and/or have an impact on each other in most cases. One 
participant involved in a public health building retrofit project reported the firm would have to include upgrading several building systems in the retrofitting project, due to the existing condition of the building (BO, Public1). To upgrade the building systems, a fire exit and a disable access are required to be constructed due to regulatory requirements. This resulted in a significant increase on total project cost. The firm thus concluded that the building was not worth retrofitting and therefore planned to demolish the building. However, because of the potential heritage tag on the building, the general community and local heritage trust were against this decision. Consequently, whether to retrofit or demolish the building was still undecided, while the seismic risk still faced the community.

\section{Assorted stakeholders involved in reaching the decision}

Another theme revealed from the data analysis is that seismic retrofit projects normally involve many stakeholders and interested parties, such as local government, historic place trust, and the general community. Decisions regarding whether or not to strengthen the earthquake-prone buildings are often affected by groups of people whose attitudes towards risk and values differ greatly. Several participants from three categories agreed taking into account of the opinions and viewpoints of assorted stakeholders during the decision making made the process more challenging, as indicated in Figure 3.

The participants in the building owner category reported that some stakeholders place different value on certain aspects, which led to disagreement on selecting viable options. One engineer observed that building owners had to demand more information of certain alternative to incorporate or respond to other stakeholder's opinion. The practice to gather more information and data was normally time-consuming and costly. Further-

\section{ASSORTED STAKEHOLDERS INVOLVED}

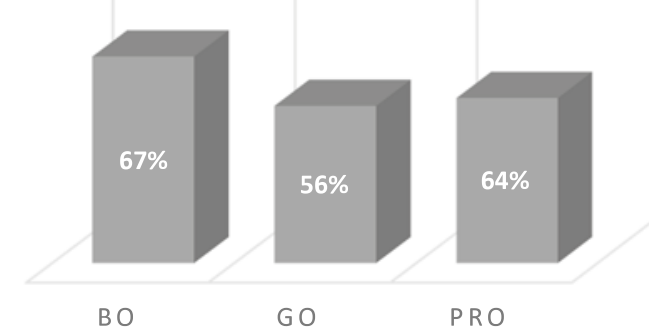

Fig. 3. The percentage of participant recognising "Assorted stakeholders involved" as a challenge more, if the disagreement among the stakeholders cannot be resolved, building owners may have to experience a lengthy legal process to obtain consent to implement the alternative building owners prefer. One participant reported: "In these cases, you have people that are empowered to prevent you from doing things on your property... We have to go through notify resource consent and spent $\$ 150,000$ just to get the right to replace the verandah (BO, Private 2)." This quote highlights the influence, mostly negative, posed by other stakeholders regarding seismic retrofitting. Such influence sometimes costs building owners considerable time and financial resources. One of the participating building owners decided to choose "do nothing" over the EPB because of potential time and financial spend to accommodate stakeholder's requirement, and thus slowing down the progress of seismic rehabilitation (BO, Public 1).

Indeed, with various stakeholders involved in the decision-making process, communication between building owners and stakeholders is unavoidable. Effective and efficient communication is a necessity to achieve an agreement among parties whose value differs on many aspects. Evidence from the findings showed that this characteristic of the decision environment leads to a major challenge in decision-making. Ineffective communication can lead to disagreement on what to do with EPBs, and eventually extend the decision-making process on seismic mitigation, or sometime deter the implementation of seismic retrofitting all together.

\section{Conflicting multiple objectives}

A total of $92 \%$ of the building owners reported multiple objectives were to be achieved through the rehabilitation project, a significant challenge in decision making. However, 33 and $55 \%$ of the participants from Government organisations and Professional practitioners, respectively, perceive it as a main challenge, as suggested in Figure 4.

The interviewed building owners listed a range of objectives were to be achieved in seismic rehabilitation projects, which varied from case to case. Although there are some common objectives identified by the building owners and professionals, such as minimising total costs and minimising business disruption, it is problematic to generate a list of uniform objectives. These fundamental objectives normally depend on the ownership of the building, portfolio of, and nature of the owners. They also heavily rely on building owners' internal economics and the characteristics of their core business. 


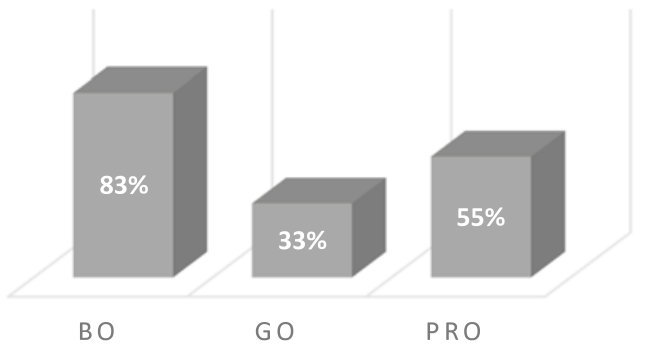

Fig. 4. The percentage of participant recognising "Conflicting multiple objectives" as a challenge

As reported by one participant, the main objective the owner wanted to achieve was to remove the legal liability imposed on the Board due to the building's earthquake-prone tag (BO, Public4).

These objectives often conflict with each other. One participant recounted that several objectives to be achieved in one of their seismic mitigation project. These objectives were "minimising total costs, maximising space for business purpose, maximising quality of exiting building inventory, and minimise service disruption (BO, Private3). The firm had to make trade-offs on these objectives due to financial restrictions. The differences of fundamental objectives, financial circumstances, and function of the building, inevitably lead to unique trade-offs considered by each building owner in accordance with their personal circumstances.

Just over half of the interviewees from the practical professionals recognised conflicting objectives as a major challenge in decision making. These participants who recognised this issue all had experience working through the decision making process with building owners and stated that various trade-off were "jagged and balanced" because of these conflicting objectives.

\section{Unaided decision making process}

Findings from the interviews showed that a high percentage (83\%) of the participated building owners made decision to retrofit in accordance with their 'natural instinct'. Figure 5 indicates that a low percentage of the governmental (22\%) and professional personnel (18\%) showed concerns regarding this issue.

Building owners indicated that they did not use any systematic analysis on their decisions regarding earthquake-prone buildings, although they were aware of some of the traditional analyses prevalent among the professionals, such as cost benefit analysis. One participant mentioned: "There

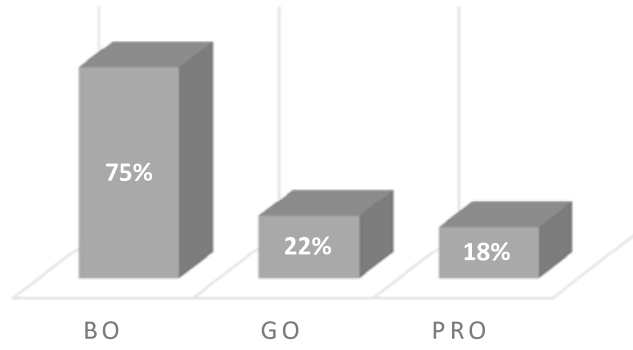

Fig. 5. The percentage of participant recognising "Unaided decision making process" as a challenge

was not really a cost benefit analysis done to see whether it was worth saving it (earthquake prone building)...Firstly, it is not necessary always come down to cost. The essential concerns we have are the liability, the age and the quality of the building. These concerns cannot be directly expressed in a cost benefit analysis (BO, Non-profit 2)."

Three building owners reported that they had difficulties in using currently established decisionmaking frameworks because of the variety of the factors in consideration, the uncertainty involved and the interrelationship among the factors. Two building owners believed that there was no techniques or methods to assist them to quantify their decision problems. They indicated that the main impediment for exercising a cost benefit analysis is that is too difficult to transfer each consideration and factor into monetary value. In most cases, what building owners were trying to achieve was non-monetary, such as removing the legal liability, having a safe building for the congregation, or having a building suitable for the users, or having a building suitable for contemporary requirements. In addition to this, there is uncertainty in determining total retrofitting costs. A cost benefit analysis is not considered to be a viable tool to evaluate the alternatives in projects such as this one.

Additionally, $82 \%$ of the professional personnel considered that a seismic mitigation implementation problem normally has 'ready-made' alternatives, such as 'do nothing' or strengthen to minimum levels. The participants of PRO group indicated that it is not difficult for engineers to develop detailed information for these alternatives. The costs, time frame and construction plan for these alternatives can be assessed with up-to-date technology. Similarly, participants of the government organisations tended to agree with the professionals. The majority of participants (almost $80 \%$ of the group) thought that building owners were provided methods and models to evaluate available 
seismic rehabilitate options. Evidence from the findings suggests significant inconsistencies exist among the interviewed stakeholders.

\section{DISCUSSION}

The research findings provide insight into why building owners are slow in reaching seismic mitigation decisions for EPBs in New Zealand. Through examining the decision environment surrounding seismic rehabilitation alternatives, the main challenges in decision-making are revealed. Various alternatives and diverse considerations in the decision making environment, conflicting multiple objectives, and assorted stakeholders to communicate with, are all factors involved in making decisions on whether and how to implement seismic mitigation measures a difficult one to reach for building owners. Documents reviewed and insights from interviews suggest that building owners tend to consider the available options during the decision-making process. Professional reports submitted to building owners all involved estimating total costs of each viable mitigation alternatives. However, these alternatives normally did not reflect diverse considerations of the decision environment or the objectives building owners would like to achieve. The professional reports were pivotal documents forming the discussion platform for all stakeholders to reach and agree on the final decision. Being alternative driven, the reports were not able to provide a basis for stakeholders exchanging opinions and considering possible trade-offs. This alternative driven decisionmaking could be the result of either the nature of the seismic mitigation decision problem and/or traditional ways of decision-making in civil engineering related field such as found here.

Indeed, the most significant finding in this paper is the inconsistency in perception whether building owners have adequate assistance in making such a decision. Most building owners have little or no knowledge about seismic retrofit performance standards, legal obligations and potential liabilities relating to earthquake risks (Nahkies 2009). "We don't have too much information (about how to manage earthquake prone buildings) available. I mean information [that] we understand (BO, Public4)." This quote highlights that although technical information is a necessity for decisionmaking, building owners lack access to seismic mitigation information. This finding is consistent with the results of Killip (2001) that the message of seismic retrofitting is not delivered in the lan- guage of the addressee - that is, building owners and decision-makers.

Hence, building owners heavily rely on professionals such as architects and engineers for explanation and advice in the decision-making process. However, since these considerations are not limited to the engineering field, building owners are not able to count on architects or engineers only. The long list of considerations in the decision-making environment inevitably leads to unique trade-offs in accordance with building owners' individual circumstances. Since these considerations are not limited to the engineering and architectural fields, advice and assistance from the consulting professional can only contribute partially to the decisionmaking process. This helps explaining the inconsistencies of whether aided decision making process are available to building owners and practical professionals.

The qualitative findings indicate that conventional decision making frameworks of seismic retrofitting are viewed by building owners as insufficient and inefficient. The conventional method of decision-making support for seismic risk mitigation is Cost Benefit Analysis (CBA). CBA is good for evaluating the profitability of public or private investment in seismic retrofitting (Zikas, Gehbauer 2007; Hopkins et al. 2006; Smyth et al. 2004; Yamin et al. 2014), and also the recommended decision-making tool to TAs in New Zealand (Department of Building and Housing 2008). Notably, the technique aims at assisting policy makers in understanding the feasibility of retrofitting existing structures (Williams et al. 2009; Mahsuli, Haukaas 2013) and selecting mitigation planning (Bostrom et al. 2006); supporting planners to evaluate mitigation measures (Smyth et al. 2004; Yamin et al. 2014); assisting investors in choosing among competing investment alternatives in seismic zones (Ergonul 2005); and helping insurance professionals to understand the estimated loss and risk (Ellingwood, Wen 2005). However, it is interesting to find that such decision-making approaches do not aim at assisting building owners, who bear the mitigation costs and undertake the liability and responsibility for EPBs.

Compared to conventional decision-making frameworks, insights from the interviews suggest building owners are in need of a systematic method that is able to address the decision-making challenges identified. The model should therefore consider the objectives building owners want to achieve, balance the requirements of various stakeholders and interested parties, and reflect 
the considerations involved in different aspects, in order to adequately evaluate options. With such an aided decision-making process, building owners should be in a better position to make an effective and efficient decision regarding their EPBs.

\section{CONCLUSION}

Findings related to research questions posed in this study provide answers to why building owners are slow in making decisions regarding seismic mitigation in New Zealand despite its high seismicity and vulnerability to earthquake risks. The challenges to seismic rehabilitation decision process were identified by examining stakeholders' decision environments. Five major issues were established, namely, various alternatives, diverse considerations, assorted stakeholders, conflicting multiple objectives, and unaided decision making. Hence, the reasons for slow progress in seismic mitigation decision making can be classified into two categories. One is the complicated decision environment itself, and the other is lacking appropriate decision making frameworks addressing the characteristics of the decision problem. The research findings further reveal the need for appropriate decision-making frameworks which help facilitating communication among stakeholders, in order to assist building owners to tackle this multi-disciplinary environment. Further research is needed in order to develop effective frameworks suitable for such decision problems that would enhance decision efficiency and quality.

Findings from this study offer plausible explanations concerning building owners' struggle to make satisfactory risk mitigation decisions. These findings can be regarded as an effort to understand the underlying challenges of successful seismic mitigation decisions, due to some research limitations. Only 32 participants were interviewed in this study because of the rigid selection criteria employed. Thus the findings may not perfectly reflect the issues for the total population from which they are drawn. Further research, such as examining decision-making process via many case studies, is important in order to develop a clearer understanding of the requirements of a muchneeded decision-making framework. Validating the characteristics of decision environment and the decision-making process, particularly in the New Zealand context, is critical in order to develop and tailor decision-making frameworks that will assist building owners to enhance the retrofit decision. Nevertheless, the challenges relating to stakehold- ers' decision context surrounding the seismic rehabilitation decision process revealed in this study provides vital information for developing optimised decision-making tools aimed at assisting building owners to reach effective and efficient seismic mitigation decision. This research is thus of practical significance to building owners, engineers and architects, and the New Zealand community as a whole.

\section{REFERENCES}

Bartels, D. M.; Bauman, C. W.; Cushman, F. A.; Pizarro, D. A.; McGraw, A. P. 2015. Moral judgment and decision making, in Keren, G.; Wu, G. (Eds.). The Wiley Blackwell handbook of judgment and decision making. Chicherster, UK: Wiley. http://dx.doi.org/10.1002/9781118468333.ch17

Bostrom, A.; Turaga, R. M. R.; Ponomariov, B. 2006. Earthquake mitigation decisions and consequences, Earthquake Spectra 22: 313-327. http://dx.doi.org/10.1193/1.2190668

Bothara, J. K.; Sharpe, R. D. 2009. Why do we still tolerate buildings that are unsafe in earthquakes?, in Proceedings of the 2009 NZSEE Conference, 3-5 April 2009, Christchurch, New Zealand. Paper No. 52.

Bradley, B. A.; Dhakal, R. P.; Cubrinovski, M.; MacRae, G. A.; Lee, D. S. 2008. Seismic loss estimation for efficient decision making, in Proceedings of the 2008 NZSEE Conference, 11-13 April 2008, Wairakei, New Zealand. Paper No. 32.

Canterbury Earthquake Royal Commission. 2012. Final report, 30 November, 2012. Wellington: Canterbury Earthquake Royal Commission.

Creswell, J. W. 2007. Qualitative inquiry and research design: choosing among five approaches. Thousand Oaks: Sage Publications.

Department of Building and Housing. 2004. The Building Act. Wellington: Brookers Ltd.

Department of Building and Housing. 2008. TA earthquake-prone buildings policy: summary of information included in policies. Department of Building and Housing.

Earthquake Engineering Research Institute. 1998. Incentives and impediments to improving the seismic performance of buildings. San Francisco: Earthquake Engineering Research Institute.

Egbelakin, T.; Wilkinson, S. 2008. Factors affecting motivation for improved seismic retrofit implementation, in Proceedings of the Australian Earthquake Engineering Conference, 21-23 November 2008, Ballarat, Australia.

Egbelakin, T.; Wilkinson, S.; Potangaroa, R.; Ingaham, J. 2013. Improving regulatory frameworks for earthquake risk mitigation, Building Research and Information 41: 1-13. http://dx.doi.org/10.1080/09613218.2013.819546

Ellingwood, B. R.; Wen, Y.-K. 2005. Risk-benefit-based design decisions for low-probability/high consequence earthquake events in Mid-America, Progress 
in Structural Engineering and Materials 7: 56-70. http://dx.doi.org/10.1002/pse.191

Ergonul, S. 2005. Economic analysis of a shopping center in seismic zone, Building and Environment 40: 1526-1532. http://dx.doi.org/10.1016/j.buildenv.2004.11.012

Eskerod, P.; Huemann, M. 2014. Managing for stakeholders, in Turner, R. (Ed.). Gower handbook of project management. Farnham: Ashgate Publishing Ltd.

FEMA. 2006. Risk management series: designing for earthquakes. FEMA.

Hopkins, D. C.; Arikan, M.; Sharpe, R. 2006. Benefitcost study for 369 apartment buildings in Istanbul, in Proceedings of the 2006 NZSEE Conference, 10-12 March 2006, Napier, New Zealand. Paper No. 32.

Killip, R. E. 2001. "Tell it like it is": how to communicate your future vision for earthquake engineering to clients and building owners, in Proceedings of the 2001 NZSEE Conference, 23-25 March 2001, Wairakei, New Zealand. Paper No. 7.03.

Lindell, M. K.; Alesch, D.; Bolton, P. A.; Greene, M. R.; Larson, L. A.; Lopes, R.; May, P. J.; Mulilis, J. P.; Nathe, S.; Nigg, J. M.; Palm, R.; Pate, P.; Perry, R. W.; Pine, J.; Tubbesing, S. K.; Whitney, D. J. 1997. Adoption and Implementation of hazard adjustments: an assessment of existing research, International Journal of Mass Emergencies and Disasters 15: 327-388.

Mahsuli, M.; Haukaas, T. 2013. Seismic risk analysis with reliability methods, part I: Models, Structural Safety 42: 54-62.

http://dx.doi.org/10.1016/j.strusafe.2013.01.003

Maxwell, J. A. 2013. Qualitative research design: an integrated approach. Thousand Oaks, CA: Sage Publications, Inc.

Ministry of Businesss Innovation \& Employment. 2013. Building (Earthquake-prone Buildings) Amendment Bill.

Nahkies, P. B. 2009. Seismic upgrading - meeting the economic challenge, in Proceedings of the 15th annual conference of the Pacific Rim Real Estate Society, 18-21 January 2009, Sydney.

NZSEE. 2006. Assessment and improvement of the structural performance of buildings in earthquake, Recommendations of a NZSEE Study Group on Earthquake Risk Buildings, June 2006, Wellington.

Paton, D.; Bajek, R.; Okada, N.; Mcivor, D. 2010. Predicting community earthquake preparedness: a cross-cultural comparison of Japan and New Zealand, Natural Hazards 54: 765-781.

http://dx.doi.org/10.1007/s11069-010-9500-2

Smyth, A. W.; Altay, G.; Deodatis, G.; Erdik, M.; Franco, G.; Gulkan, P.; Kunreuther, H.; Lus, H.; Mete, R.; Seeber, N.; Yuzugullu, O. 2004. Probabilistic benefit-cost analysis for earthquake damage mitigation: evaluating measures for apartment houses in Turkey, Earthquake Spectra 20: 171-203. http://dx.doi.org/10.1193/1.1649937

Solberg, C.; Rossetto, T.; Joffe, H. 2010. The social psychology of seismic hazard adjustment: re-evaluating the international literature, Natural Hazards and Earth System Sciences 10: 1663-1667. http://dx.doi.org/10.5194/nhess-10-1663-2010

Spence, R. 2004. Risk and regulation: can improved government action reduce the impacts of natural disasters?, Building Research and Information 32: 391402. http://dx.doi.org/10.1080/0961321042000221043

Stevens, C. M.; Wheeler, K. F. 2008. Implementing earthquake prone building policy under the Building Act 2004 - Wellington City's approach, in Proceedings of the 2008 NZSEE Conference, 11-13 April 2008, Wairakei, New Zealand. Paper No. 70.

$\mathrm{Su}, \mathrm{R} .2009$. The motivations and investment preferences of Chinese investors who migrate to New Zealand, PhD Thesis, Auckland University of Techonology.

Tierney, K. 2004. Effective strategies for hazard assessment and loss reduction: the importance of multidisciplinary and interdisciplinary approaches. Natural Hazards Research and Applications Information Center.

Williams, R. J.; Gardoni, P.; Bracci, J. M. 2009. Decision analysis for seismic retrofit of structures, Structural Safety 31: 188-196. http://dx.doi.org/10.1016/j.strusafe.2008.06.017

Yamin, L.; Hurtado, A.; Rincon, R.; Barbat, A. H.; Reyes, J. 2014. Use of non-linear dynamic analysis in the assessment of seismic vulnerability of buildings, in Proceedings of the Second European conference on Earthquake engineering and seismology, 25-29 August 2014, Istanbul, Turkey. http://dx.doi. org/10.13140/2.1.3217.9528

Zikas, T.; Gehbauer, F. 2007. Decision process and optimization rules for seismic retrofit programs, in Proceedings of the International Symposium on Strong Vrancea Earthquakes and Risk Mitigation, 4-6 October 2007, Bucharest, Romania, 472-484. 